\title{
Diversification, Coordination Costs and Organizational Rigidity: \\ Evidence from Microdata
}

First submitted: August 27, 2007

This version: July 2, 2009

Evan Rawley

The Wharton School

University of Pennsylvania

2021 SH-DH

3620 Locust Walk

Philadelphia PA 19104

rawley@wharton.upenn.edu

215-746-2047

Key words: Diversification, coordination costs, organizational rigidity, productivity 


\section{Diversification, Coordination Costs and Organizational Rigidity: Evidence from Microdata}

\footnotetext{
Abstract: This paper examines the impact of coordination costs and organizational rigidity on the returns to diversification. The central thesis is that coordination costs offset economies of scope, while organizational rigidity increases coordination costs, further constraining economies of scope. The empirical tests of this proposition identify the effects of coordination and organizational rigidity costs on business-unit and firm productivity, using novel data from the Economic Census on taxicab and limousine firms. The key results show that coordination and organizational rigidity costs are economically and statistically significant, while organizational rigidity itself accounts for a $16 \%$ decrease in paid ride-miles per taxicab in incumbent diversifiers, controlling for the other costs and benefits of diversification and incumbency. The findings suggest that coordination costs, in general, and organizational rigidity costs, in particular, limit the scope of the firm.
} 


\section{Introduction}

When firms diversify into new business segments, economies of scope are achieved by coordinating production decisions across new and legacy business units (Teece 1980, 1982). While there may be aggregate benefits of coordination, coordination is not costless. Resources that were optimized ex ante, with respect to maximizing business unit performance, may be underutilized ex post, as business-unit decisions are sublimated to serve the greater good of the overall firm. Moreover, coordination is achieved by modifying contractual structures and routines (Williamson, 1999; Nelson and Winter, 1982). To the extent that organizational change is not frictionless, organizational rigidity increases the coordination costs of diversification and constrains economies of scope by creating a barrier to adaptation. Consistent with the prior literature, the paper defines coordination costs as costs that arise from managing task interdependencies (Jones and Hill, 1987; Gulati and Singh, 1998) and organizational rigidity as the cost of reformulating (or failing to reformulate) previously institutionalized routines and practices in legacy businesses (Leonard-Barton, 1992; Kaplan and Henderson, 2005). While understanding how firms respond organizationally to the challenges of diversification is of great importance, there has been little emphasis on coordination and organizational rigidity costs in the diversification literature, perhaps because of the difficulty scholars face distinguishing between different types of diversification costs.

The paper develops and tests two propositions: first, that coordination costs act as an offset to economies of scope for diversifiers, particularly in related diversification when 
achieving synergies depends upon coordinating activities across divisions; and second, that organizational rigidity increases coordination costs, further constraining economies of scope, because institutionalized organizational routines and practices are costly to change. The propositions are tested using a unique data set, consisting of detailed establishment-level observations on every major taxicab and limousine fleet in the United States, for the years 1992 and 1997, from the Economic Census. Taxicabs offer an industrial context that is particularly well-suited for analysis of coordination costs and organizational rigidity, as the taxicab segment of the ground passenger transportation industry is comprised of thousands of firms producing roughly homogenous outputs in hundreds of heterogeneous geographically isolated markets. The homogenous nature of production in the taxicab industry allows for the creation of an economically meaningful comparative measure of firm performance, while exogenous variation in local markets identifies the impact of diversification on productivity.

The empirical tests identify the productivity effects of coordination and organizational rigidity costs, in the context of related diversification. Although the organizational rigidity analysis does not distinguish between the direct costs of adapting existing organizational systems and the foregone efficiency costs of failing to adapt following diversification, the paper estimates the cumulative effect of the costs of organizational rigidity, associated with diversification. The results show that both coordination costs and organizational rigidity costs, net of other costs and benefits of diversification and incumbency, are economically and statistically significant, with organizational rigidity 
itself accounting for a $16 \%$ decrease in paid ride-miles per taxicab in incumbent diversifiers.

The paper makes two distinct contributions to the literature. First, it fills a gap in the diversification literature by empirically testing for the existence of coordination costs as an offset to economies of scope. Second, the paper takes a step toward integrating the insights of the organizational rigidity literature with the literature on firm scope by developing and testing a theory of how organizational rigidity influences the returns to diversification.

\section{Theory and related literature}

Since Rumelt (1974), the strategy literature has emphasized synergies that arise from related diversification. Synergies, or economies of scope, are, by definition, benefits that firms achieve through coordinating production across business units that cannot be achieved when production is optimized independently within business units (Teece, 1980, 1982). While synergy results from coordination, achieving synergy comes at the cost of implementing and maintaining coordinated production (Hill and Hoskisson, 1987). Thus, realized economies of scope associated with diversification are equal to potential economies of scope less the costs of implementing new coordination procedures.

Coordination costs are costs that arise from organizational interdependencies (Jones and Hill, 1987). While in theory the costs of organizational interdependency might include 
all of the costs of diversification, the literature on the costs of diversification typically focus on corporate-level agency costs. For example, corporate managers may diversify the firm to protect their jobs (Amihud and Lev, 1981), to increase the value of their skills to the firm (Shleifer and Vishny, 1991), or to build empires (Jensen, 1986). Agency costs may also arise between corporate managers and operating managers in diversifying firms because corporate managers' efficient span of control is limited by their ability to adequately monitor the activities of diverse business units (Penrose, 1959; Schoar 2002). Internal capital markets represent one important mechanism by which corporate managers can destroy value, either because they are poorly informed about operating units or because managers engage in ill-advised corporate "socialism" (Lamont, 1997; Scharfstein and Stein, 2000). Similarly, Rajan, Servaes and Zingales (2000) discuss how influence costs arise in diversified firms when operating units lobby the corporate center for corporate largess.

While the literature on the costs of diversification delivers a number of important insights, costs are usually conceptualized as value destroying mistakes made by corporate managers. Thus, the main theoretical thrust of the literature on the costs of diversification has been about the efficiency of the corporate center following diversification, and the main question the empirical literature on the costs of the diversification has grappled with is whether diversification destroys value (Wernerfeldt and Montgomery, 1988; Lang and Stulz, 1994; Berger and Ofek, 1995; Campa and Kedia, 2002; Villalonga, 2004). 
This paper takes a different approach. Rather than focusing on corporate-level agency costs, the paper considers the impact of coordination costs on the firm's operating units, following diversification. This emphasis on coordination costs builds on the insights of the early theoretical literature on diversification, which proposes that coordination costs are manifest at the operating unit level as a cost of substituting corporate governance for market governance (Jones and Hill, 1988). Thus, coordination costs are conceptually distinct from corporate-level agency costs in that they are costs of coordinating production across business units, even when the corporate center acts in good faith, effectively monitors its business units, provides appropriate incentives, and efficiently allocates capital.

As in Hoskisson and Hitt (1988), this paper proposes that coordination costs should always be non-zero unless optimizing each business unit independently also optimizes both jointly, in which case there is no need to integrate them. Yet, if each business unit can be optimized on a stand-alone basis, altering the organization of any business unit to achieve coordination benefits across business units must sub-optimize the stand-alone value of that business unit. Thus, diversification increases firm value at the cost of suboptimizing at least one business unit's stand-alone organization.

The theory proposed is consistent with Levinthal and $\mathrm{Wu}$ (2006), who conceptualize the benefits and costs of diversification in terms of the impact of integration on capacity constrained versus scale free resources. Synergy arises when joint production increases utilization of scale free resources, whereas coordinated production is costly when it taxes 
capacity constrained resources. In their model, net profit from sharing resources within a firm includes both the costs and benefits of diversification with respect to shared resources.

While Levinthal and $\mathrm{Wu}$ (2006) describe conditions necessary for diversification to create value, the coordination cost literature implies that achieving synergies from shared resources is not a sufficient condition for determining whether diversification creates value because diversifying firms also encounter bureaucratic costs of coordinating resources (Jones and Hill, 1987). In Jones and Hill (1987) achieving synergies from shared resources leads firms to reorganize, sub-optimizing the utilization of non-shared resources by blunting operating unit incentives or imposing rules and procedures that hinder decentralized decision making. Thus, coordination costs associated with both shared and non-shared resources are expected to be positive, even when realized economies of scope are positive.

The insight that non-shared activities and resources may be sub-optimized by diversification is particularly important for understanding why diversification increases coordination costs, even when integration primarily takes place at the corporate level. Indeed, it is precisely the goal of pursuing potential synergies that leads to coordination costs. The first hypothesis, therefore, predicts that related diversification in pursuit of potential synergies leads to coordination costs that act as an offset to realized economies of scope. 
Hypothesis 1: In diversifying firms, coordination costs attenuate realized economies of scope.

The first hypothesis predicts the existence of coordination costs in diversified firms. To refine our understanding of the mechanisms underlying coordination costs the paper builds on the insights of organizational theory, particularly the idea that routines and contracts are costly to change once they are institutionalized, which Kaplan and Henderson (2005) call organizational rigidity. ${ }^{1}$

The concept of organizational rigidity is closely related to Leonard-Barton's (1992) proposition that the very routines that create competitive advantage in firms are vulnerable to becoming "core rigidities", or sources of competitive disadvantage, when firms confront environmental changes. Tushman and Anderson (1986) discuss a similar phenomenon in their research on the impact of technological discontinuities on firm performance. They find that competency destroying technological change render existing techniques obsolete, forcing firms to undergo a costly process by which they acquire new skills, ability and knowledge. Henderson and Clark (1990) build on this insight to propose that certain kinds of technological change can destroy organizational capital accumulated in incumbents, allowing start-ups to outperform them. This paper builds on and extends the prior conceptions of organizational rigidity by including foregone

\footnotetext{
${ }^{1}$ The paper focuses on organizational rigidity, as opposed to organizational inertia or structural inertia, a concept frequently used to study population-level organizational change (Hannan and Freeman; 1977, 1984). While organizational rigidity and organizational inertia are related concepts, in that they both make predictions about organizational adaptation costs, the former applies to rational choices firms make as they trade off coordination costs and economies of scope, while the latter applies best to population-level selection effects and does not make a clear prediction about how diversification influences the operations of the firm (Kelly and Amburgey, 1991).
} 
productivity opportunities as well as the costs associated with renegotiating contracts. The paper also extends the implications of rigid organizations beyond contexts where there are exogenous technological discontinuities, positing that organizational rigidity is a common friction faced by all incumbent firms contemplating organization changes, and of particular importance when firms pursue synergies through coordination.

In the context of diversification, organizational rigidity can be seen as an additional cost of pursuing potential economies of scope, further limiting realized economies of scope associated with horizontal integration. Figure 1 shows how the concept of organizational rigidity adds a new dimension to extant models of coordination costs by illustrating the relationships between diversification, economies of scope (potential and realized), coordination costs, and organizational rigidity.

$* * * * * * * * * * * * * * * * * * * * * * * * * * * * * *$
$* * * * \mathrm{FIGURE} 1 \mathrm{ABOUT} \mathrm{HERE} * * * *$
$* * * * * * * * * * * * * * * * * * * * * * * * * * * * * *$

When firms diversify, they reorganize their operating units to create value by altering existing routines and contracts. A theory of organizational rigidity predicts that reorganization is costly, in the sense that it destroys tacit knowledge embedded in existing processes, creates incentive problems when contracts are re-negotiated, and produces frictions that lead to foregone productivity opportunities. For example, more rigid firms will allow higher levels of cannibalization and will engage in less cross- 
selling to avoid a more extensive overhaul of their legacy operations. In the language of Levinthal and $\mathrm{Wu}$ (2006), organizational rigidity increases coordination costs associated with non-shared resources reducing the benefits of resource sharing. This insight leads directly to the second hypothesis: organizational rigidity increases coordination costs, taxing the productivity of diversifying firms through direct adaptation costs and indirect costs of foregone opportunities.

Hypothesis 2: Organizational rigidity increases coordination costs reducing realized economies of scope.

The second hypothesis predicts that coordination costs are increasing in organizational rigidity, while economies of scope are decreasing in organizational rigidity. While past work has focused on the costs of structuring new activities and cross-unit interconnections to capture new synergies (Hill and Hoskisson, 1987; Jones and Hill, 1988), this paper examines organizational rigidities - the costs of changing (or not changing) previously institutionalized routines and practices in legacy businesses. Since existing organizations are, by definition, more rigid than start-up organizations, organizational rigidity costs are particular to incumbent firms, while coordination costs are common to all diversified firms. The key testable implication of organizational rigidity, in the context of diversification, is, therefore, that the productivity advantage focused incumbents typically have over focused start-ups will shrink when both incumbents and start-ups are diversified. 
By considering how organizational change associated with diversification influences competition between start-ups (de novo entrants) and diversifying incumbents, the paper builds on and extends a nascent body of research, which may be called the de novo and de alio (lateral) entry literature. Carroll, Bigelow, Sidel, and Tsai (1996) and Khessina and Carroll (2008) present evidence that lateral entrants - firms that enter a new business from within an industry - tend to survive longer than start-ups in scale intensive industries. In related work, Klepper and Simons (2000) compare different types of lateral entrants into the television manufacturing industry and find that pre-entry experience facilitates different levels of knowledge spillovers in R\&D. This paper builds on the de novo and de alio literature by explicitly considering how entry status influences the returns to diversification. While the de novo and de alio literature typically focuses on firm survival in the new business as the key outcome variable, this paper focuses on business unit productivity as the key measure of firm performance. Diversified firms may outlast focused firms because they have deep pockets or less variable cash flows, reasons unrelated to productivity. Thus, the finding that diversification leads to falling productivity is complementary to the de novo and de alio literature, suggesting that economies of scope also play a role in determining competitive advantage in the competition between de novo and de alio entrants.

\section{Institutional Background}

The taxicab segment of the ground passenger transportation industry (hereafter the "taxicab industry") is particularly well-suited for studying the productivity consequences 
of coordination costs and organizational rigidity, in the context of diversification. One attractive feature of the taxicab industry is that it is a local business with regulated prices. Since taxicab markets are geographically segmented, the nationwide taxicab industry is actually a collection of hundreds of independent city-level markets, providing considerable variation to identify the effects of interest. I exploit the fact that firms face regulated prices, in their local markets, to develop a precise and economically meaningful measure of firm performance that can be interpreted as physical output per unit of input. Furthermore, the level of horizontal integration between taxicabs and limousines changed dramatically during the sample period due to widespread regulatory changes, creating a quasi-natural experiment in lateral diversification. $^{2}$

Prior to the 1990 s taxicab and black car operations were strictly legally separated by local regulation. Following the high-profile "Freedom Cab" case (Jones v. Temmer) in Colorado in 1993, which was not directly related to cross-ownership, state legislatures became increasingly involved in mitigating these conflicts by passing laws wresting regulatory authority over limousines from local regulators (Cox, 1993). As regulatory limitations on cross ownership were removed private-for-hire fleets began to operate both taxicabs and limousines.

The logic behind expanding from taxicab into limousine services is straightforward. Limousine services represent a higher priced, differentiated service, produced in a

\footnotetext{
${ }^{2}$ For so freely sharing the wealth of knowledge they have accumulated regarding the U.S. taxicab industry, I am indebted to: C.J. Christina, Jason Diaz, Thomas Drischler, John Hamilton, Stan Faulwetter, Alfred La Gasse, Kimberly Lewis, Joe Morra; Marco Henry, John Perry, David Reno, Aubby Sherman, Doug Summers, and especially Craig Leisy.
} 
manner that is qualitatively similar to taxicab services. For example, fleets recruit drivers, acquire vehicles and permits, match drivers to cars as well as schedule and deliver rides to passengers. Multidivisional (e.g., taxicab and limousine) fleets attempt to spread their fixed costs, in each of these functions, across the boundaries of the taxicab and limousine businesses. Taxicab firms also report that they up-sell taxicab customers to limousines where possible, employing limousines to meet unmet taxicab demand during peak times to smooth overall capacity utilization.

Taken together, the advantages of integration can be substantial. However, taxicab fleet operators also describe several coordination-related costs of operating both taxicabs and limousines in the same fleet. Firms face capacity utilization challenges immediately following diversification. Implementing new contracts and monitoring systems often frustrates existing drivers, leading to defections. Diversifying firms often face customer defections as well, particularly when customers are required to participate in new protocols, such as administering vouchers to employees. Moreover, managing two types of drivers, vehicles, incentive schemes and customers can create complexity and conflicts that are difficult to manage. For example, taxicab managers observed that, following diversification, they spent more time on recruiting independent drivers, customer relationship issues and managing conflicts between taxicab and limousine drivers, managerial challenges not faced by taxicab fleet operators that focus on transactional spot-market exchange. 
In addition, variation in incentive schemes ${ }^{3}$ can lead to coordination failures, particularly channel conflict when taxicab drivers refuse to cede lucrative rides to limousines, and decreased utilization of taxicabs (cannibalization), as fleets steer higher value rides toward limousines. While cannibalization directly offsets the gross benefits of up-selling, steering can also lead to more pernicious outcomes, as taxicab drivers subvert the dispatching system by picking up fares intended for limousines, thereby creating chaos in the dispatching system.

Firms may respond to internal conflicts by keeping their dispatching processes separate, but this also reduces the benefits of integration. Rather than maintaining separate dispatching operations, diversifiers tend to change their contracting practices, with respect to asset ownership, to manage cannibalization, contracting more extensively with owner-operators who are better able than shift-drivers to operate in a more complex dispatching environment. ${ }^{4}$ Organizational changes at diversifying taxicab firms are illustrative of the broader set of issues diversifying firms face. Diversifiers choose between capturing operational synergies, by adapting organizationally and closely coordinating the operations of different business units, and avoiding the coordination costs of diversification, by keeping businesses separate.

There appear to be significant coordination costs as well as benefits from operating an integrated taxicab and limousine firm. The key question, with respect to the second

\footnotetext{
${ }^{3}$ Firms face an important moral hazard problem because they cannot monitor taxicab driver effort. The near-ubiquitous solution is for taxicab drivers to be compensated with high-powered incentives. By contrast, monitoring is much easier in the black car business, since most rides are dispatched. Therefore, black car drivers often are compensated with lower-powered incentives.

${ }^{4}$ Rawley and Simcoe (2009) discuss diversification and outsourcing to owner-operators in more detail.
} 
hypothesis, predicting that organizational rigidity increases coordination costs, is whether incumbent firms can shift to the new organizational optimum costlessly or whether their existing contracts and routines constrain their ability to adapt relative to a diversified start-up. Anecdotally, firms report diversification-related costs that stem from organizational adaptations: retraining dispatchers, re-contracting with drivers and renegotiating with clients. If coordination costs and organizational rigidity are not only salient, but also economically meaningful, we should see their effects on business unit and firm productivity. To formally test for coordination costs and organizational rigidities in the production function, the paper turns to the data.

\section{Data and Measures}

The core dataset for this paper comes from the 1992 and 1997 Economic Census. The Economic Census includes every taxicab and limousine firm in the United States with at least one employee (SIC code 412100 [taxicabs] and 411920 [limousines]). The comprehensiveness of the database is extremely useful as it allows us to track every incumbent firm with at least one employee over time and to observe every new and lateral entrant into the taxicab and limousine market in 1997. The database contains detailed establishment-level data on firm revenue, line of business revenue at the six-digit industry level, number of vehicles by type (e.g., taxicab vs. limousine) and geographic identifiers. $^{5}$

\footnotetext{
${ }^{5}$ Less than $1 \%$ of establishments were in firms that had multiple locations. Using an alternative sample that excluded multi-establishment firms had no effect on the results.
} 
The 1992 and 1997 Economic Census contain complete records on 1,020 and 1,106 observations, respectively; on taxicab firms with at least two taxicabs; $\$ 10,000$ of taxicab revenue; and, at least, two taxicab fleets in their market (county). ${ }^{6}$ I use all of the complete observations for computing total factor productivity and for cross-sectional tests of the impact of diversification and entry status on productivity. ${ }^{7}$ The cross-sectional samples consist of approximately $30 \%$ of all taxicab firms (with at least one employee) and between $50-65 \%$ of the $\$ 1$ billion taxicab industry. For tests of the impact of diversification on within-firm business-unit-specific asset utilization, I use the subset of firms that existed and reported complete data in both 1992 and $1997(n=560)$. The within-firm changes sample includes approximately half the firms and about $70 \%$ of revenue in the cross sectional regressions.

Table 1 shows the descriptive statistics for both the cross-sectional data sets and the within-firm changes set. Table 1 reveals that in 1992, 99\% of taxicab firms were single product firms. By 1997, 62\% of taxicab firms also operated limousines (40\% are incumbents while $22 \%$ are start-ups). I define lateral diversifiers from taxicab to limousine operations as those firms that had SIC code 412100 and no limousines in their fleet in 1992, but had at least one limousine in their fleet by $1997 .{ }^{8}$

\footnotetext{
${ }^{6}$ Approximately 2,000 observations, in 1992 and 1997, are not used because they do not contain the number of taxicabs in their fleet. This set is primarily composed of administrative record (AR) observations - very small firms that the Economic Census does not actually survey but rather imputes values for. Using alternative samples, with more or less stringent sample restrictions, led to the same qualitative findings.

${ }^{7}$ Firms that existed in 1992, but were small or reported incomplete data, are properly treated as incumbents (rather than start-ups) in 1997 cross sectional regressions.

${ }^{8}$ Alternative measures of lateral entry, including measures that required taxicab firms to have a certain fraction (e.g., 10\%) of their vehicle capital in limousines or attain a certain percentage (e.g., 10\%) of their revenue in limousines were very highly correlated with the "single limousine" measure of lateral entry and yielded qualitatively identical results.
} 
Empirical tests on taxicab performance, which is defined in terms of productivity as in Hill and Snell (1989), are facilitated by the relatively simple and homogenous production function in the taxicab industry, which minimizes measurement error in the key reducedform establishment-level productivity measures I employ. I define the profit function in the usual way with two parameters that link profitability and productivity to the firm's entry and diversification status. Profit $\pi$ for an input and output price-taking firm $i$, in business-unit $j=\{$ Taxicab, Limousine $\}$, and geographic market $m$, which can be represented by:

$$
\text { (1) } \begin{aligned}
\pi_{\mathrm{i}} & =\left(\mathrm{p}_{\mathrm{Tm}}-\mathrm{c}_{\mathrm{Tm}}\right) \mathrm{Y}_{\mathrm{iT}}(\theta, \sigma)+\left(\mathrm{p}_{\mathrm{Bm}}-\mathrm{c}_{\mathrm{Bm}}\right) \mathrm{Y}_{\mathrm{iB}}(\theta, \sigma)-\mathrm{F}\left(\mathrm{K}_{\mathrm{i}}, \sigma\right), \\
\mathrm{Y}_{\mathrm{j}} & =\mathrm{A}_{\mathrm{ij}}(\theta, \sigma) \mathrm{K}_{\mathrm{ij}}{ }^{\beta \mathrm{k}} \mathrm{L}_{\mathrm{ij}}{ }^{\beta 1},
\end{aligned}
$$

where $Y$ is output in units (ride-mile equivalents or "rides" assuming miles per ride are approximately constant across vehicles within a market), subscripts $T$ and $B$ index taxicab and limousine operations; F>0 is the fixed cost of operations, where fixed costs are increasing in total capital $(\mathrm{K})$ and scope $(\sigma)$. The market price per ride $\mathrm{p}>0$ and the cost of selling an additional ride $\mathrm{c}>0$ convert physical output into gross profit, where physical output $Y$ is generated by a production function that transforms inputs capital $(\mathrm{K})$ and labor (L) using technology (A), which can be interpreted as total factor productivity in quantities (TFPQ). ${ }^{9}$ The two key parameters $\theta=\{0,1\}$ and $\sigma=\{0,1\}$ index whether the

\footnotetext{
${ }^{9}$ Since the taxicab and limousine industry production function is approximately Leontief, the labor term is dropped in the final specification (equation (2)) below.
} 
firm is an incumbent or start-up, and whether the firm is diversified or focused, respectively.

It is clear from equation (1) that potential fixed cost savings play an important role in determining firm strategy with respect to economies of scope. Therefore, caution must be used when interpreting differences in productivity as differences in profitability. The key assumption required to connect productivity to profitability is that fixed costs are independent of entry status $\theta$, as is evident in equation (1). ${ }^{10}$

When market prices are fixed and labor is used proportionately to capital, as in the taxicab market, total factor productivity in quantities (TFPQ) ${ }^{11}$ can be computed for a focused establishment $i$, at time $t$ is as the residual of a regression ${ }^{12}$ of a time-specific intercept $\alpha$, a market-level fixed effect $\lambda$, and the log of establishment-specific capital $k$, on the log of dollar denominated revenue $r$ as in:

$$
\text { (2) } r_{i t}=\alpha_{t}+\lambda_{m t}+\beta_{t} k_{i t}+T F P Q_{i t} \text {. }
$$

The key feature of (2) is that $T F P Q$ can be interpreted as a measure of physical asset utilization relative to other fleets in the same market that is standardized to have mean

\footnotetext{
${ }^{10}$ Additionally, to calculate the impact of differences in productivity on differences in profit, holding fixed costs constant, productivity also has to be scaled by gross margin $=(\mathrm{p}-\mathrm{c}) / \mathrm{p}$.

${ }^{11}$ See Foster, Haltiwanger and Syverson (2008) for a detailed derivation of TFPQ

${ }^{12}$ As in Solow (1957) total factor productivity is estimated as the residual from a production function.
} 
zero within market (county). ${ }^{13}$ To calculate pooled (taxicab and limousine) productivity, $r$ is $\log$ pooled revenue and $k$ is $\log$ pooled capital. ${ }^{14}$

\section{Specification}

Changes in taxicab productivity following diversification into limousines

The baseline test measures the effect of diversification on within-firm changes in taxicab productivity. I implement this test by taking differences in productivity, at the firm level from 1992 and 1997, to eliminate unobservable time-invariant firm characteristics that influence productivity and using (3):

(3) $\Delta \mathrm{TFPQ}_{\mathrm{i}}=\mathrm{B}_{0}+\cdot \mathrm{B}_{1} \Delta \mathrm{STATUS}_{\mathrm{i}}+\mathbf{X}_{\mathbf{c}, \mathbf{i}} \mathbf{B}_{\mathbf{c}}+\mathrm{e}_{\mathrm{i}}$,

where $\triangle T F P Q$ is the change in taxicab productivity as defined above and $\triangle S T A T U S$ is a categorical variable that captures whether the firm diversified during the sample period. $\boldsymbol{X}_{\boldsymbol{c}, \boldsymbol{i}}$ is a vector of controls that could plausibly shift the supply or demand structure of the local taxicab market including: legal form of organization $^{15}$; size; changes in local market population; changes in the number of taxicabs in the market; changes in the number of limousines in the market; and $e$ is an error term. Since taxicab capital under

\footnotetext{
${ }^{13}$ TFPQ is winsorized at the $1^{\text {st }}$ and $99^{\text {th }}$ percentiles, though doing so has no impact on the results.

14 The pooled calculation can only be interpreted as total factor productivity (TFP) since limousine prices are not regulated at the local level. While TFPQ is ideal, TFP delivers a useful, if imperfect, measure of multi-factor productivity.

${ }^{15}$ Legal form of organization is defined as the firm's tax status as reported to the IRS, which is coded as a categorical variable equal to one if the firm is a corporation and zero otherwise. Alternative specifications that used a vector of legal forms of organization, including corporation, partnership, sole-proprietorship and co-operative had no effect of the results.
} 
management is included as a continuous variable in the first stage of the total factor productivity calculation, size is included non-parametrically in the second stage, using categorical variables for each third of the size distribution. The results are robust to alternative measures of size and to specifications that include firm-level fixed effects. ${ }^{16}$

\section{Identification strategy}

The key factor identifying the tests of the first hypothesis, which predicts coordination costs offset (realized) economies of scope, is that market-level characteristics exogenously influence the firm's decision to diversify. In the ideal experiment, we would randomly assign the "treatment" diversification, and factors of production, and observe how productivity changed in the treatment group compared to a control group. Measuring within-firm changes in productivity, in the presence of a regulatory shock, reduces the need for an alternative identification strategy. However, one cannot be certain that there are not time-varying firm-specific shocks that are correlated with diversification and the outcome variables of interest. In particular, we might be concerned that firms diversify after being exposed to negative productivity shock. Diversifying in response to unobserved negative productivity shocks is a threat to causal inference because an exogenous shock to firm strategy sets (e.g., the regulatory change) does not prevent endogenous firm choice from biasing OLS estimates.

\footnotetext{
${ }^{16}$ Because there are only two time periods equation (3) is estimated in first differences to eliminate the effect of time invariant unobserved firm specific characteristics, rather than using firm fixed effects.
} 
I address endogeneity issues using lagged (e.g., 1992) concentration of limousines in the firm's market as an instrumental variable (IV) for the entry decision. Lagged concentration of limousines in the firm's market is a good instrument for horizontal entry, since incumbent firms will be more interested in entering the limousine market when it is not dominated by a major player. When a few major players dominate a market, it is usually because they have developed deep relationships in the lucrative corporate market for limousine service. High limousine concentration also represents an entry barrier because concentrated competition increases the threat of retaliation. ${ }^{17}$ Furthermore, lagged market concentration of limousines should not affect changes in any given firm's productivity levels (relative to other firms in the same market). Results are robust to alternative instruments that proxy for the degree of competition in the local limousine market and to correcting for selection effects based on all observable characteristics of firms using propensity score matching.

\section{Diversification and the costs of organizational rigidity}

Estimating the impact of diversification and entry status on the costs of organizational rigidity in cross-section requires some additional assumptions. The key identifying assumption is that fixed costs are independent of entry status conditional on firm scope. The fixed cost assumption seems reasonable given the nature of the industry as fixed costs are typically embedded in facilities, dispatching systems and back-office labor,

\footnotetext{
${ }^{17}$ Retaliation could be economic or physical. A number of sources have noted the connection between the ground passenger transportation industry and organized crime, making the threat of physical conflict a very real consideration in the industry. Celona (2004a and 2004b) reports explicit connections between organized crime and intimidation of limousine drivers.
} 
which should not differ between start-ups and incumbents conditional on the scope of the operation. I formulate the connection between total factor productivity and the costs of organizational rigidity more formally in the appendix.

To test the second hypothesis that the productivity gap between incumbents and start-ups will shrink, when both incumbents and start-ups are diversified, I use (4):

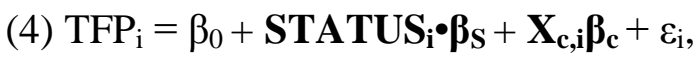

where subscript $t$ is suppressed because the cross-sectional tests are all performed in1997, TFP is multifactor productivity in the pooled (taxicab and limousine) regressions and total factor productivity in quantities (TFPQ) in the taxicab-only regressions, STATUS is a vector of dummies that capture the interaction between entry status and firm scope (e.g., single product incumbent, lateral diversifier, taxicab-only start-up, diversified entrant). $\boldsymbol{X}_{\boldsymbol{c}, \boldsymbol{i t}}$ is a vector controls as above, except that the controls are in levels rather than in changes, and $\varepsilon$ is an error term.

Taking differences $d_{l}$ in the coefficients that measure the relative productivity of single product start-ups and single product incumbents, $\left[d_{l}=\left(\beta_{\mathrm{s}} \mid\right.\right.$ taxicab-only start-up $)-\left(\beta_{\mathrm{s}} \mid\right.$ taxicab-only incumbents)] establishes the net incumbency advantage. I then use the difference $d_{2}$ in the coefficients that measure the relative productivity of taxicab and limousine start-ups and lateral diversifiers, $\left[d_{2}=\left(\beta_{\mathrm{s}} \mid\right.\right.$ taxicab and limousine start-ups $)$ $\left(\beta_{\mathrm{s}} \mid\right.$ lateral diversifiers)], to establish the combined effect of a change in scope and the 
advantages of incumbency. The difference in these two differences, $\mathrm{C}(\delta)=d_{1}-d_{2}$, recovers the net cost of organizational rigidity - the main test of the second hypothesis. While the empirical tests identify organizational rigidity costs by comparing diversified incumbents against diversified start-ups, the existence of the latter is only a convenient empirical device. Conceptually, organizational rigidity costs act as a barrier to adaptation for incumbents, whether or not startups enter as diversified firms.

\section{Results and Discussion}

\section{Diversification and coordination costs}

Figure 2 shows the kernel density distributions of taxicab total factor productivity (TFPQ) for future diversifiers and non-diversifiers in 1992 (panel A) and diversifiers and non-diversifiers in 1997 (panel B). Visually diversification appears to have a significant effect on the relative productivity of diversified firms' taxicabs. Table 2 estimates of the impact of diversification on taxicab utilization more precisely. Column (1a) shows that lateral entry into the limousine business is correlated with a within-firm change in taxicab productivity of $-0.45(-36 \%)$ and is significant at the $1 \%$ level. ${ }^{18}$

The inclusion of a number of exogenous firm and market level controls reduces the point estimate to $-0.41(-34 \%)$ without affecting the statistical significance of the result (column 2a). Changes in the competitive dimensions of the market, e.g., the number of

\footnotetext{
${ }^{18}$ The percentage change in productivity is computed from the coefficient estimate on diversification according to 1- $\exp \left(\mathrm{B}_{1}\right)$, for $\mathrm{B}_{1}<0$.
} 
taxicabs and limousines operated by other fleets, do not have much influence on the costs of lateral expansion because differencing total factor productivity, at the market level, leaves little variation to be explained by changes in these variables. The coefficient on changes in taxicab ownership rates in other fleets is positive and significant because permit prices are correlated with expected positive future productivity shocks. When permit prices rise, drivers are more likely to face wealth constraints, limiting independent ownership of taxicabs. However, the economic magnitude of the effect is small at $5 \%$ $(0.20 \times 0.27)$ in the average market.

$* * * * * * * * * * * * * * * * * * * * * * * * * * * * * *$ ****FIGURE 2 ABOUT HERE****

$* * * * * * * * * * * * * * * * * * * * * * * * * * * * * *$

Since the decision to diversify laterally is endogenous, the OLS results discussed above can only be interpreted as correlations. To control for the endogeneity of the lateral entry strategy with the change in productivity, I use the lagged level of concentration of limousines (L-HHI) in the firm's market as an instrument for lateral entry, where $L-H H I$ is expected to be strongly negatively correlated with lateral entry. Column (1b) shows 2SLS estimates of the effect of diversification on changes in productivity. The first-stage results are strong (F-statistic of 32) and in the direction expected, indicating that the instrument is powerful and operating as predicted (see first stage summary statistics at the bottom of column 1b). The point estimate on diversification in the univariate 2SLS specification is $-0.53(-41 \%)$ and is significant at the $1 \%$ level. The results are 
qualitatively unchanged with controls (column 2b). The interpretation is that there is a causal relationship between lateral entry and falling taxicab business-unit productivity.

The results support the contention of the first hypothesis, which predicts the existence of coordination costs at the operating division level, but are incomplete with respect to organizational rigidity costs. To test the second hypothesis, I turn to cross-sectional evidence.

\section{Diversification and organizational rigidity}

Figure 3 shows the kernel density plots of the cross-section of taxicab-only productivity for the four types of firms in the sample \{taxicab-only incumbents, incumbent diversifiers, taxicab-only start-ups, and diversified start-ups $\}$. It is clear from the figure that the productivity advantage of incumbency is smaller for diversified firms than for focused taxicab firms. Table 3 shows the estimate of the cost of organizational rigidity $C(\delta)$, which is derived from the relative productivity estimates of the four types of firms in the sample (see the appendix for the explicit formulation of the relationship between productivity and the costs of organizational rigidity). Overall, pooled (taxicab and limousine) performance is examined as a robustness check to understand whether the taxicab-only productivity effect of diversification can be explained by differences in productivity in limousines between start-ups and incumbents. 
As in the within-firm regressions, the results of the cross-sectional regressions show large economic and statistical effects of diversification on productivity. The table also shows a pattern consistent with the assumption that start-ups are generally disadvantaged compared to incumbent firms. The main cross-sectional productivity results are presented in columns 1 and 2, using the taxicab-only production characteristics and the taxicab-only subset. Column 1 shows the results without controls, where the excluded category is incumbent firms who did not expand into limousines. The $T F P Q$ of start-up taxicab fleet is 0.23 below the mean of incumbent firms, while taxicab to limousine diversifiers and diversified start-ups fall 0.66 and 0.67 below TFPQ of incumbents who did not expand into limousines. The difference in the productivity gap between focused and diversified start-ups and incumbents in the taxicab-only case is $-0.21(-19 \%$ of TFPQ). ${ }^{19}$ Adding a number of controls, in Table 3, for exogenous firm and market-level characteristics reduces the coefficient estimates slightly to -0.17 (-16\% of TFPQ) and the result continues to be significant at the $5 \%$ level (column 2 , bottom). ${ }^{20}$ The results provide support for coordination costs as the mechanism acting to offset synergies, as predicted by the first hypothesis, since the cross-sectional tests implicitly control for agency costs as well as economies of scope associated with diversification; and for the second hypothesis, which predicts that organizational rigidity increases coordination costs and constrains economies of scope.

\footnotetext{
${ }^{19}$ The difference in the productivity gap between focused and diversified start-ups and incumbents is calculated as the difference in the coefficient estimates on STATUS, C $(\delta)=d_{1}-d_{2}$, where $\left[d_{l}=\left(\beta_{\mathrm{s}} \mid\right.\right.$ taxicab-only start-up) - ( $\beta_{\mathrm{s}} \mid$ taxicab-only incumbents $\left.)\right]$ and $\left[d_{2}=\left(\beta_{\mathrm{s}} \mid\right.\right.$ taxicab and limousine start-ups $)$ - $\left(\beta_{\mathrm{s}}\right.$ | lateral diversifiers)]. In Table 3 column (1), $\mathrm{d}_{1}=-0.23, \mathrm{~d}_{2}=-.01$ and $\mathrm{C}(\delta)=-0.21$. I use STATA's lincom command to calculate the standard error of $\mathrm{C}(\delta)$, which is computed as the square-root of a weighted sum of the squared standard errors of the coefficient estimates.

${ }^{20}$ Total factor productivity in quantities (TFPQ) can be interpreted as changes in paid ride miles per vehicle.
} 
$* * * * * * * * * * * * * * * * * * * * * * * * * * * * * *$

****FIGURE 3 ABOUT HERE****

$* * * * * * * * * * * * * * * * * * * * * * * * * * * * * *$

Robustness of cross-sectional tests

One potential problem with interpreting the declining taxicab-only productivity gap between incumbents and start-ups, when both are diversified, is that incumbents may be more productive than start-ups in limousines. Indeed, if part of the measured organizational rigidity effect reflects the superior cross-selling ability of incumbents, then lower taxicab utilization may reflect higher limousine utilization, which we may mistake as organizational rigidity. To address this issue, I examine whether measured organizational rigidity costs change when accounting for pooled revenues and capital stock. Table 3 column 3 shows that taxicab to limousine diversifiers' and diversified start-ups' multifactor productivity is far below incumbents who do not diversify (the excluded group), while diversified start-ups and focused (taxicab only) start-ups are -0.26 $(-23 \%$ of TFP) behind. In column (3), the adjustment cost estimate is $-0.26(-23 \%$ of TFP) and significant at the $5 \%$ level. Adding a vector of controls, in column 4, has a small effect on the estimate of organizational adjustment costs. Although the pooled results measure $T F P$ and not $T F P Q$, and are therefore not as precise as the taxicab-only estimates, they provide some additional evidence that organizational rigidity has real economic implications. 
The key identifying assumption, in the cross-sectional tests, is that start-ups decide to diversify using the same selection process that incumbents follow. This assumption appears to be reasonable given that 1992 productivity levels were almost identical for both future diversifiers and future non-diversifiers, and that the 2SLS results in Table 2 showed that the selection effect biases the OLS productivity results toward zero. Therefore, for incumbents, we can be reasonably confident that variation in ability (e.g., 1992 productivity) does not drive the diversification decision and that, on average, firms that earn the highest marginal returns from diversification choose to do so. If start-ups also choose whether to diversify based on how good they are at diversifying and not based on unobservable quality differences between firms, the assumption holds, and the cross-sectional results are well identified. ${ }^{21}$

\section{Discussion}

One potential concern with the estimated organizational rigidity effect is that a decline in paid ride miles per vehicle of $16 \%$ (see Table 3 column 2, bottom) is larger than one might have expected a priori. $^{22}$ At least two caveats are in order in interpreting the

\footnotetext{
${ }^{21}$ I also verify the robustness of the falling taxicab productivity following diversification result to other plausible alternative explanations that have little to do with organizational change, including (1) diversification causing the firm to under invest in productivity enhancing technology and (2) diversification causing the firm to shift investments away from the taxicab business toward the limousine business. With respect to diversification and investment in technology (1), I find that diversification is indeed correlated with lower levels of adoption of new dispatching technology, and that new dispatching technology is associated with higher productivity for adopters. However, diversification effects swamp non-adoption effects in regressions on changes in productivity that include both factors. With respect to shifting investments to limousines (2), I find that diversifying firms invest almost 50\% more in new taxicab-specific assets than do non-diversifiers, controlling for their size before diversification. Thus, diversifiers expand their limousine and taxicab businesses simultaneously, which is inconsistent with the alternative hypothesis that diversifiers shift investment away from taxicabs. Results are available from the author upon request. ${ }^{22}$ Although on its face $16 \%$ seems like a large effect several industry participants reported (anecdotally) much larger declines in taxicab productivity.
} 
magnitude of the estimated organizational rigidity effect. First, changes in ride miles per vehicle do not translate directly into changes in profits per vehicle because taxicabs are only being driven empty a portion of the time they are not utilized. Instead firms and drivers take shifts off the market and/or shorten shift hours. If we re-estimated taxicab capacity in terms of taxicab up-time, the utilization effect would be smaller. However, the ride-miles per vehicle measure is still a useful measure of productivity as firms can always sell their taxicab to another firm with a higher marginal utilization rate. Second, the $16 \%$ decline in paid ride miles per vehicle is not necessarily the long-run steady state effect of diversification as diversified firms may end up selling their marginal taxicabs rather than running them under-utilized. Thus, the organizational rigidity effect may attenuate over time.

The existence of coordination costs supports Jones and Hill's (1987) contention that there are unique risks of related diversification. Achieving synergies comes at the cost of coordinating activities between business units, making related diversification a high-risk, high-reward activity.

The existence of organizational rigidity costs, in the context of diversification, has important implications for firm strategy. If organizational rigidity imposes adaptation costs on existing organizational systems then firms possessing valuable but fragile organizational assets, such as tacit knowledge embedded in routines, should be wary of pursuing strategies that rely on achieving operational synergies, since organizational change taxes the efficiency of the existing nexus of contracts and routines. More 
fundamentally, organizational rigidity implies that a firm's competitors may be able to achieve synergies at a lower cost, even when the focal firm is more productive.

\section{Limitations}

The decision to diversify depends on the associated costs and benefits, as well as the regulatory environment, which may determine whether the choice is available. This paper quantifies some of the costs of integration, but does not quantify all of the potential benefits - particularly the long-run benefits. Thus, it is not surprising that we observe a great deal of integration despite the existence of organizational rigidity costs. Future research might extend this work by exploiting a longer time series to understand the persistence of coordination costs and organizational rigidities.

A second important limitation to this research is that coordination costs and the costs organizational rigidity are not observed directly, but rather are estimated by exploiting variation in firm strategies and geographic markets. Furthermore, the analysis does not distinguish between adaptation cost and non-adaptation cost components of organizational rigidity. A further limitation of this paper is the inability to measure the extent of task differentiation between business units, which is conjectured to influence the magnitude of the organizational rigidity effects. Measuring coordination and organizational rigidity costs directly, as well as understanding adaptation versus nonadaptation costs and exploring the relationship between task differentiation and organizational rigidity represent opportunities for future research. 
Finally, the findings of this paper are limited to a single industry and, therefore, the results should be generalized cautiously as the magnitude and nature of organizational rigidities may vary extensively across industries. Nevertheless the results of this work seem broadly applicable to industrial contexts where economies of scope are gained by sublimating the organization of one line of business to the overall objectives of the firm. ${ }^{23}$

\section{Conclusion}

This paper proposes and tests two related propositions: (1) that coordination costs, the costs that arise from managing task interdependencies, offset economies of scope and (2) that organizational rigidity, the costs of reorganizing legacy business unit activities, increase coordination costs, further constraining economies of scope in diversifying firms. Conceptually, organizational rigidity includes both costs that arise directly from organizational adaptation and indirect costs of foregone productivity gains when adaption is too expensive to undertake.

The paper exploits a quasi-natural experiment in diversification, using a rich and novel micro-data set on taxicab firms to test the influence of diversification on firm performance. Within firm changes in taxicab utilization is substantially negative

\footnotetext{
${ }^{23}$ For example, consider Starbucks's recent experience selling hot sandwiches at their coffee shops. The company began selling hot sandwiches in 2004, believing that there were economies of scope inherent in serving coffee and hot food together, but found the "scent of the warm sandwiches interferes with the aroma of the stores that serving hot food ... and [got in the way of employees'] ability to make the perfect shot of espresso" (Starbucks Press Release, 2008). While it is difficult to disentangle coordination costs from the costs of organizational rigidity from press releases, the problems Starbucks faced with their hot sandwich line of business are illustrative of the costs of horizontal expansion as discussed in this paper.
} 
following diversification. Comparing the productivity of diversified and focused startups and incumbent firms reveals that, controlling for the benefits of diversification, the productivity advantage incumbents have over start-ups is reduced by $16 \%$, when both are diversified. I interpret these differences in productivity as evidence of coordination costs and organizational rigidity.

The existence of coordination and organizational rigidity costs, in the context of diversification, has implications for the study of firms as organizations more broadly. In particular, we might expect coordination and organizational rigidity costs to act as a brake on horizontal diversification strategies. More generally, organizational rigidities impose a hurdle for any strategy that requires organizational change. Diversification, vertical integration, geographical dispersion, merger activity, and reengineering decisions are all potentially influenced by the costs organizational rigidity. Thus, organizational rigidity helps explain the limits to firm change and growth. Moreover, the finding that start-ups are more flexible than incumbents, in the context of diversification, suggests that start-ups may be more flexible than incumbents, in general. While others have argued start-ups respond more effectively than incumbents to technological change, this paper provides evidence that start-ups are also more nimble in a broader sense. 


\section{Acknowledgements}

I am grateful to Kira Fabrizio, John Freeman, Bronwyn Hall, David Hsu, Olga Khessina, Francine Lafontaine, David Levine, Alex Mas, Robert McMillan, John Morgan, David Mowery, Eric Rasmusen, Anne Rawley, Tim Simcoe, Jason Snyder, Chad Syverson, Steve Tadelis, participants in seminars at Cornell University, Georgetown, Harvard Business School, HKUST, Indiana University, INSEAD, Northeastern University, the University of California Berkeley, UCLA, USC, Washington University and the Wharton School, two anonymous referees and the editor for helpful suggestions. The research in this paper was conducted while I was a Census Bureau research associate at the California Census Research Data Center (CCRDC). I thank the Census Bureau and Ritch Milby in particular. Research results and conclusions expressed are my own and do not necessarily indicate concurrence by the Bureau of Census. This paper has been screened to insure that no confidential data are revealed. Financial support for this work was provided by fellowships from the Ewing Marion Kauffman Foundation and the Institute of Management, Innovation and Organization (IMIO) at the University of California Berkeley. 


\section{References}

Amihud Y, Lev B. 1981. Risk Reduction as a Managerial Motive for Conglomerate mergers. Bell Journal of Economics 12 (2): 605-617.

Berger PG, Ofek E. 1995. Diversification's Effect on Firm Value. Journal of Financial Economics 37 (1): 39-65.

Boorstin RO. 1986. Agency to Make Rules for Nonmedallion Cabs. The New York Times. December 10, 1986: B3.

Campa, JM, and Kedia S. 2002. Explaining the Diversification Discount, Journal of Finance 57 (4), 1731-1762.

Carroll GR, Bigelow LS, Seidel MDL, Tsai LB. 1996. The Fates of De Novo and De Alio Producers in the American Automobile Industry 1885-1981. Strategic Management Journal 17 (S1): 117-137.

Celona L. 2004. Limo Thugs in Extort Bust. New York Post 20 November: 15.

Celona L. 2004. Cops Bust Limo Mob ‘Enforcer’. New York Post 23 November: 28.

Cox GD. 1993. Tackling Taxis: First Step?. The National Law Journal June: 1-3.

Foster L, Haltiwanger J, Syverson C. 2008. Reallocation, Firm Turnover, and Efficiency: Selection on Productivity or Profitability? American Economic Review 98 (1): 394-425.

Gulati R, Singh H. 1998. The Architecture of Cooperation: Managing Coordination Costs and Appropriation Concerns in Strategic Alliances. Administrative Science Quarterly 43 (4): 781-814.

Hannan MT, Freeman J. 1977. The Population Ecology of Organization. American Journal of Sociology 82(5): 929-964.

Hannan MT, Freeman J. 1984. Structural Inertia and Organizational Change. American Sociological Review 49 (2): 149-164.

Henderson R, Clark K. 1990. Architectural Innovation: The Reconfiguration of Existing Product Technologies and the Failure of Established Firms. Administrative Science Quarterly 35: 9-30.

Hill CWL, Hoskisson RE. 1987. Strategy and Structure in the Multiproduct Firm, Academy of Management Review 12(2): 331-341. 
Hill CWL, Snell SA. 1989. Effects of Ownership Structure and Control on Corporate Productivity. Academy of Management Journal 32(1): 25-46.

Hill CWL, Hitt MA, Hoskission RE. 1992. Cooperative Versus Competitive Structures in Related and Unrelated Diversified Firms. Organization Science 3(4): 501-521.

Hoskisson R, Hitt MA. 1988. Strategic Control Systems and Relative R\&D Investment in Large Multiproduct Firms. Strategic Management Journal 9 (6): 605-621.

Jensen MC, Meckling WH. 1976. Theory of the Firm: Managerial Behavior, Agency Costs and Ownership Structure. Journal of Financial Economics 3 (4): 305-360.

Jensen MC. 1986. Agency Costs of Free Cash Flow, Corporate Finance, and Takeovers. American Economic Review 76 (2): 323-329.

Jones GR, Hill CWL. 1988. Transaction Cost Analysis of Strategy-Structure Choice. Strategic Management Journal, 9(2): 159-172.

Kaplan S, Henderson R. 2005. Inertia and Incentives: Bridging Organizational Economics and Organizational Theory. Organization Science 16 (5): 509-521.

Kelly D, Amburgey TL. 1991. Organizational Inertia and Momentum: A Dynamic Model of Strategic Change. The Academy of Management Journal 34 (3): 591-612.

Khessina, OM, Carroll GR. 2008. Product Demography of De Novo and De Alio Firms in the Optical Disk Drive Industry, 1983-1999. Organization Science, 19 (1): 25-38.

Klepper S, Simons KL. 2000. Dominance by Birthright: Entry of Prior Radio Producers and Competitive Ramifications in the U.S. Television Receiver Industry. Strategic Management Journal 21 (10/11): 997-1016.

Lang LHP, Stulz RE. 1994. Tobin's q, Corporate Diversification and Firm Performance. Journal of Political Economy 102 (6): 1248-1280.

Leonard-Barton D. 1992. Core Capabilities and Core Rigidities: A Paradox in Managing New Product Development. Strategic Management Journal 13 (S1): 111-125.

Levinthal D, Wu B. 2006. The Rational Tradeoff between Corporate Scope and Profit Margins: The Role of Capacity Constrained Capabilities and Market Maturity. Working Paper.

Nelson R, Winter S. 1982. An Evolutionary Theory of Economic Change. Cambridge, MA: Harvard University Press.

Penrose E. 1959. The Theory of the Growth of the Firm. New York: John Wiley. 
Rajan R, Servaes H, Zingales L. 2000. The Cost of Diversity: The Diversification Discount and Inefficient Investment. Journal of Finance 55 (1): 35-80.

Rawley E, T.S. Simcoe. 2009. Related Diversification and Outsourcing in the Taxicab Industry. Working Paper.

Rumelt RP. 1974. Strategy, Structure and Economic Performance. Graduate School of Business Administration, Harvard University: Boston.

Schoar A. 2002. Effects of corporate Diversification on Productivity. Journal of Finance 57 (2): 2379-2403.

Scharfstein DS, Stein JC. 2000. The Dark Side of Internal Capital Markets: Divisional Rent-Seeking and Inefficient Investment. Journal of Finance 55 (6): 2537-2564.

Shleifer A, Vishny RW. 1991. Takeovers in the '60s and '80s: Evidence and Implications. Strategic Management Journal 12 (S2): 51-59.

Solow RM. 1957. Technical Change and the Aggregate Production Function. The Review of Economics and Statistics 39 (3): 312-320.

Taxicab, Limousine and Paratransit Association Fact Book: Limousine and Sedan Division. 2004. Kensington, Maryland. International Taxicab Association.

Teece, DJ. 1980. Economies of Scope and the Scope of the Enterprise. Journal of Economic Behavior and Organization 1(3): 223-247

Teece, DJ. 1982. Towards and Economic Theory of the Multiproduct Firm. Journal of Economic Behavior and Organization 3(1): 39-63.

Tushman ML, Anderson P. 1986. Technological Discontinuities and Organizational Environments. Administrative Science Quarterly 31 (3): 439-465.

Villalonga B. 2004. Diversification Discount or Premium? New Evidence from the Business Information Tracking Series. The Journal of Finance 59 (2): 479-506.

Williamson O. 1999. Strategy Research: Governance and Competence Perspectives. Strategic Management Journal 20 (12): 1087-1108. 
Figure 1 Interrelationships between the main variables of interest

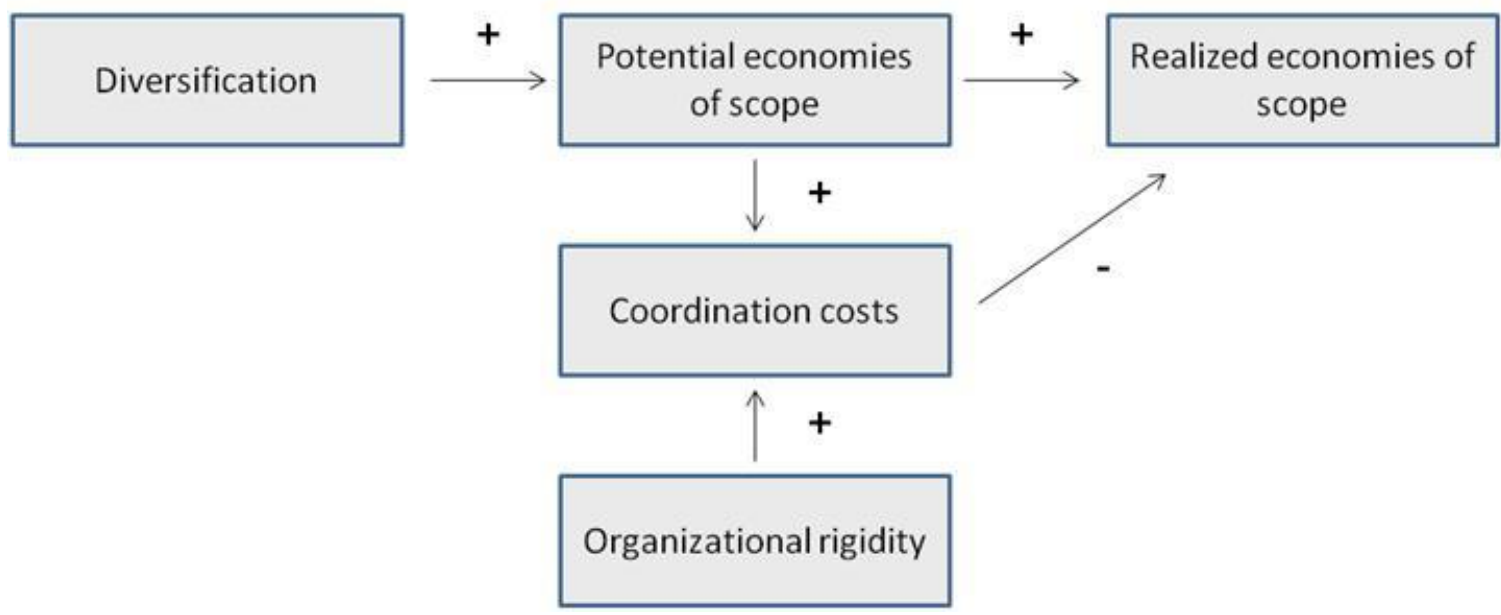




\section{Figure 2 Changes in the distributions of total factor productivity **}

Panel A: Distribution of 1992 total factor productivity (TFPQ)

Total factor productivity conditional on future diversification status $\left(T F P Q_{i 1992} \mid \sigma\right)$

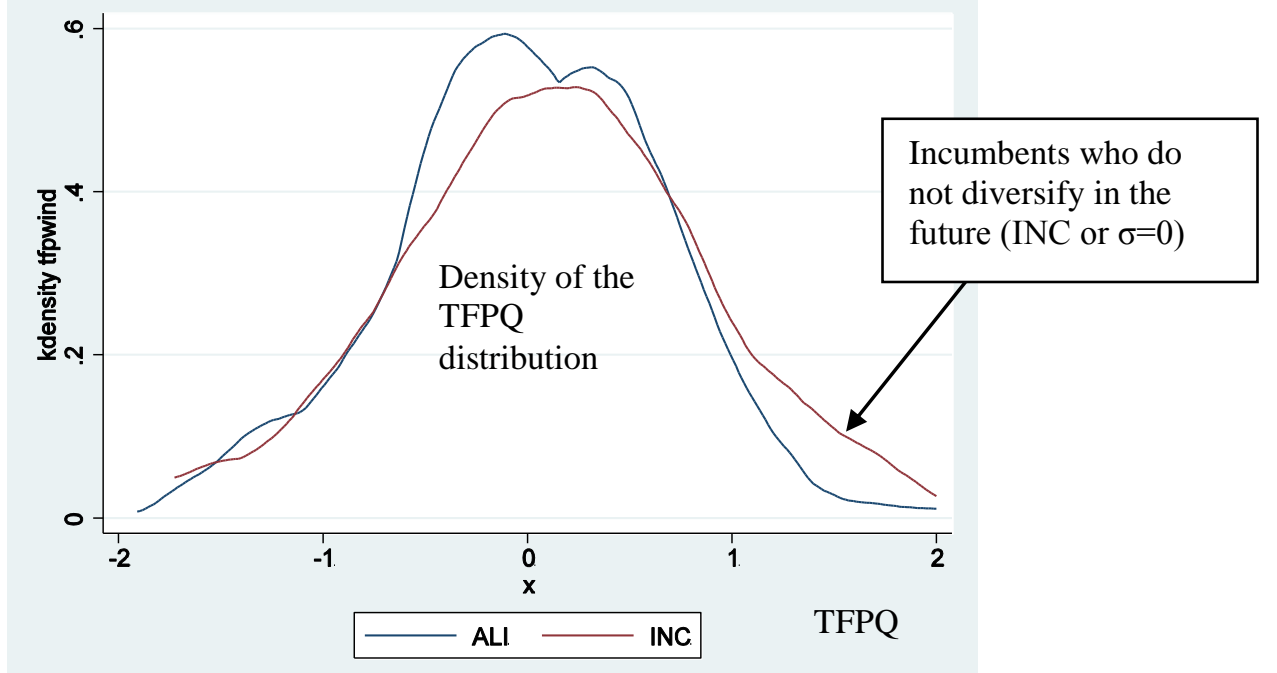

This figure shows a kernel density plot of the distribution of taxicab total factor productivity (TFPQ) in 1992 conditional on (future) diversification $(\sigma) . \mathrm{n}=560$

** See Table 2 for regression output that compares the means of this distribution with the means of the 1997 taxicab total factor productivity (TFPQ) distribution

\section{Panel B: Distribution of 1997 total factor productivity (TFPQ)}

Total factor productivity conditional on diversification status $\left(T F P Q_{i 1997} \mid \sigma\right)$

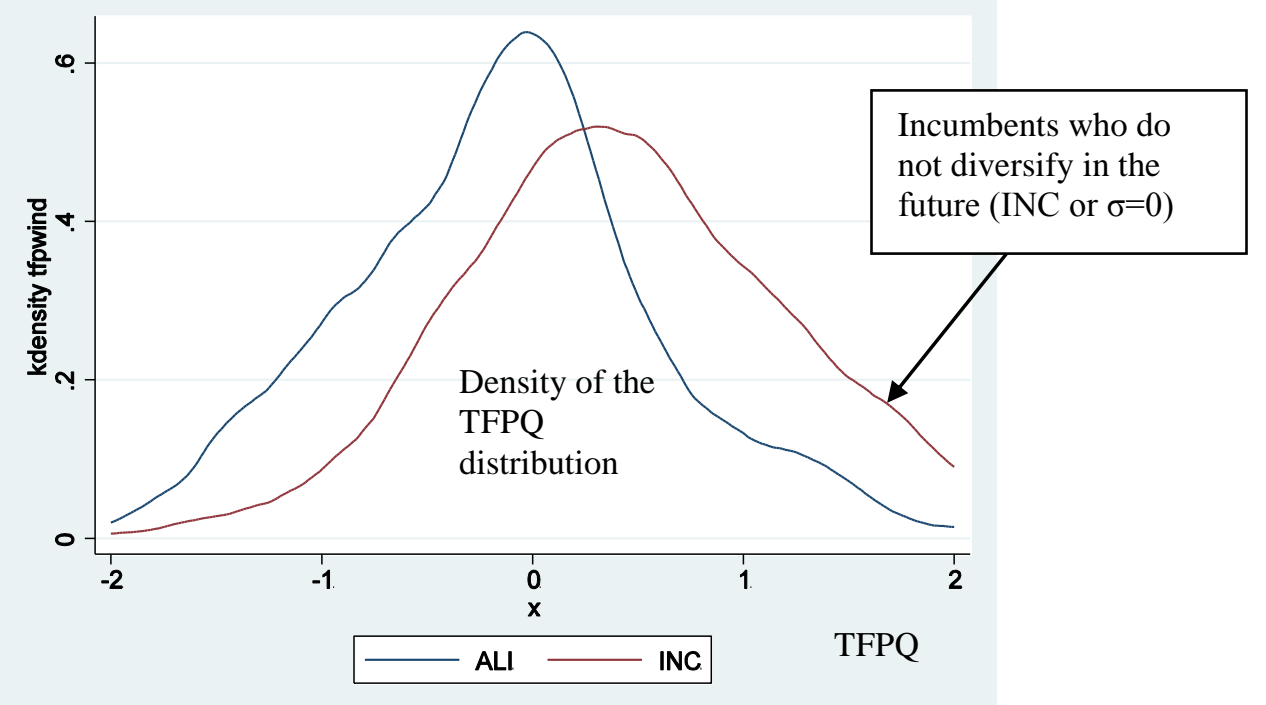

This figure shows a kernel density plot of the distribution of taxicab total factor productivity (TFPQ) in 1997 conditional on diversification $(\sigma) . n=560$

** See Table 2 for regression output that compares the means of this distribution with the means of the 1992 taxicab total factor productivity (TFPQ) distribution 
Figure 3 Distributions of taxicab-only total factor productivity (TFPQ) $* *$

1997 total factor productivity conditional on diversification and entry status $\left(\triangle T F P Q_{i} \mid \sigma, \theta\right)$

Taxicab incumbents who diversify into limousines (ALI or $\sigma=1, \theta=1$ )

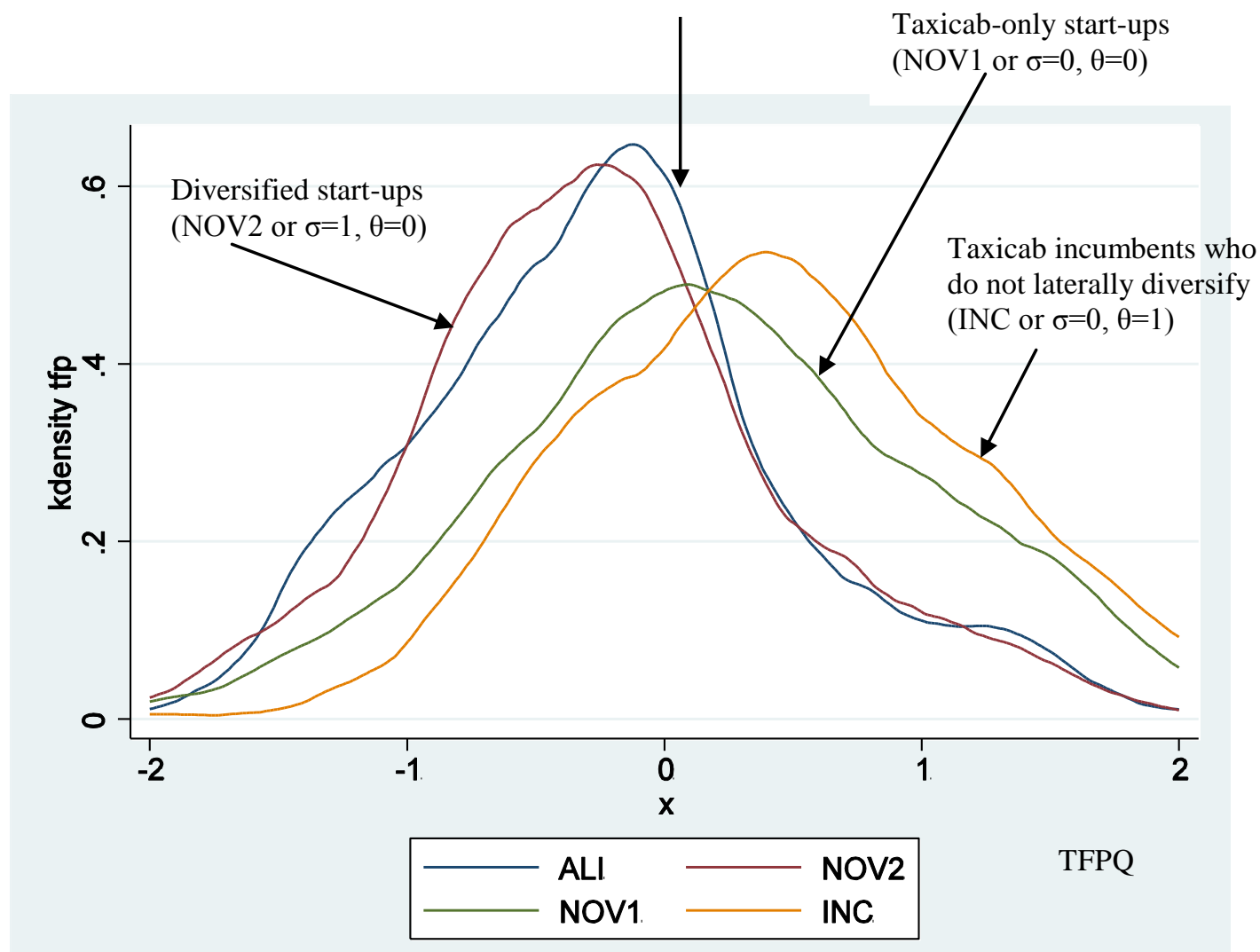

This figure shows a kernel density plot of the distribution of taxicab total factor productivity (TFPQ) in 1997 conditional on diversification $(\sigma)$ and entry status $(\theta) . n=560$

** See Table 3 for regression output that compares the four means of these distributions

ALI $=$ Diversified firm $(\sigma=1, \theta=1)$; INC $=$ Incumbent who did not diversify $(\sigma=0, \theta=1)$; NOV1 $=$ Taxicabonly start-up $(\sigma=0, \theta=0)$; NOV2 $=$ Diversified start-up $(\sigma=1, \theta=0)$ 
Table 1 Descriptive statistics

\section{Panel A - 1992 and 1997 cross sections of taxicab and limousine fleets}

\begin{tabular}{|lrrrrrr|}
\hline & \multicolumn{2}{c}{$(1)$} & \multicolumn{2}{c}{$(2)$} & \multicolumn{2}{c|}{$(3)$} \\
& Taxicab fleets only & \multicolumn{2}{c}{ Taxicab fleets only } & \multicolumn{2}{c|}{ Taxicab \& Limo } \\
& 1992 (n=1020) & $1997(\mathrm{n}=1106)$ & $1997(\mathrm{n}=2341)$ \\
& Mean & Std dev & Mean & Std dev & Mean & Std dev \\
TFPQ / multifactor TFP & 0.00 & 0.70 & 0.00 & 0.79 & -0.01 & 0.95 \\
Total revenue (\$000) & 511 & 1694 & 965 & 2491 & 650 & 2321 \\
Taxicab revenue (\$000) & 511 & 1694 & 595 & 2157 & 324 & 1524 \\
Taxicab + limousine capital (\$000) & 185 & 874 & 431 & 1342 & 349 & 1017 \\
Taxicab capital (\$000) & 185 & 874 & 227 & 1104 & 168 & 647 \\
Total vehicles (taxicab + limousine) & 18 & 61 & 39 & 81 & 33 & 76 \\
Total taxicabs & 18 & 61 & 26 & 74 & 22 & 73 \\
Fleets with 2 taxicabs / vehicles & 0.32 & 0.47 & 0.11 & 0.31 & 0.09 & 0.28 \\
Fleets with 3-5 taxicabs / vehicles & 0.21 & 0.41 & 0.32 & 0.47 & 0.31 & 0.43 \\
Fleets with 6-10 taxicabs / vehicles & 0.17 & 0.38 & 0.19 & 0.39 & 0.20 & 0.39 \\
Fleets with 11-25 taxicabs / vehicles & 0.15 & 0.36 & 0.19 & 0.39 & 0.19 & 0.38 \\
Fleets with 26-50 taxicabs / vehicles & 0.07 & 0.25 & 0.08 & 0.27 & 0.09 & 0.26 \\
Fleets with >50 taxicabs / vehicles & 0.08 & 0.27 & 0.12 & 0.32 & 0.12 & 0.31 \\
Fleet owned taxicabs (share) & 0.83 & 0.37 & 0.56 & 0.34 & 0.58 & 0.35 \\
Focused incumbent & 0.99 & 0.38 & 0.25 & 0.43 & 0.14 & 0.35 \\
Taxicab \& limousine diversifier & $\mathrm{n} / \mathrm{a}$ & $\mathrm{n} / \mathrm{a}$ & 0.40 & 0.49 & 0.54 & 0.41 \\
Focused start-up & $\mathrm{n} / \mathrm{a}$ & $\mathrm{n} / \mathrm{a}$ & 0.12 & 0.33 & 0.09 & 0.28 \\
Taxicab \& limousine start-up & $\mathrm{n} / \mathrm{a}$ & $\mathrm{n} / \mathrm{a}$ & 0.22 & 0.41 & 0.23 & 0.42 \\
Taxicab firm exits after 1992 & 0.34 & 0.47 & $\mathrm{n} / \mathrm{a}$ & $\mathrm{n} / \mathrm{a}$ & $\mathrm{n} / \mathrm{a}$ & $\mathrm{n} / \mathrm{a}$ \\
Future taxicab to limo diversifier & 0.26 & 0.43 & $\mathrm{n} / \mathrm{a}$ & $\mathrm{n} / \mathrm{a}$ & $\mathrm{n} / \mathrm{a}$ & $\mathrm{n} / \mathrm{a}$ \\
Taxicabs in the county & 270 & 534 & 626 & 772 & 520 & 741 \\
Limousines in the county & 145 & 276 & 322 & 482 & 244 & 390 \\
Limo market concentration (HHI) & 0.04 & 0.12 & 0.23 & 0.27 & 0.26 & 0.32 \\
County population (000) & 1238 & 1152 & 1231 & 1236 & 1123 & 1547 \\
County square miles & 723 & 1501 & 778 & 1534 & 951 & 2056 \\
Sole proprietor & 0.10 & 0.30 & 0.12 & 0.33 & 0.14 & 0.35 \\
Partnership & 0.02 & 0.14 & 0.02 & 0.15 & 0.03 & 0.17 \\
Cooperative & 0.03 & 0.16 & 0.02 & 0.13 & 0.01 & 0.11 \\
& & & & & & \\
\hline
\end{tabular}

Panel A columns (1) and (2) include all firms with SIC codes 4121 (taxicabs) or 4119 (limousines), taxicab revenue $\geq \$ 10 \mathrm{~K}$, at least 2 taxicabs, and at least 2 taxicab fleets in their market (county) in either 1992 or 1997. Panel A column (3) includes all firms with SIC codes 4121 (taxicabs) or 4119 (limousines), total (taxicab + limousine) revenue $\geq \$ 10 \mathrm{~K}$, at least 2 vehicles (taxicabs + limousines), and at least 2 fleets (taxicab + limousine) in their market (county) in 1997 Note that Census Bureau restrictions prohibit publication of minimum and maximum variable values. 
Table 1 Descriptive statistics (continued)

Panel B - Balanced panel of taxicab fleets

\begin{tabular}{|lrrrr|}
\hline $\mathrm{n}=560$ & $\begin{array}{r}1992 \\
\text { Mean }\end{array}$ & Std dev & Mean & Std dev \\
& & & & \\
TFPQ & 0.05 & 0.68 & 0.11 & 0.80 \\
Taxicab revenue $(\$ 000)$ & 675 & 1900 & 849 & 2739 \\
Taxicab capital $(\$ 000)$ & 230 & 930 & 319 & 1294 \\
Total taxicabs & 21 & 63 & 33 & 79 \\
Fleets with 2 taxicabs & 0.27 & 0.44 & 0.09 & 0.29 \\
Fleets with 3-5 taxicabs & 0.19 & 0.39 & 0.22 & 0.42 \\
Fleets with 6-10 taxicabs & 0.19 & 0.39 & 0.20 & 0.40 \\
Fleets with 11-25 taxicabs & 0.17 & 0.38 & 0.21 & 0.40 \\
Fleets with 26-50 taxicabs & 0.09 & 0.29 & 0.10 & 0.30 \\
Fleets with >50 taxicabs & 0.10 & 0.30 & 0.17 & 0.38 \\
Fleet owned taxicabs (share) & 0.86 & 0.33 & 0.63 & 0.36 \\
Taxicab to limousine diversifier & $\mathrm{n} / \mathrm{a}$ & $\mathrm{n} / \mathrm{a}$ & 0.54 & 0.50 \\
Taxicabs in the county & 228 & 480 & 472 & 673 \\
Limousines in the county & 103 & 228 & 221 & 414 \\
Limo market concentration (HHI) & 0.05 & 0.13 & 0.32 & 0.36 \\
County population $(000)$ & 885 & 1036 & 985 & 1148 \\
County square miles & 861 & 1642 & 878 & 1714 \\
Sole proprietor & 0.14 & 0.35 & 0.14 & 0.35 \\
Partnership & 0.02 & 0.13 & 0.02 & 0.15 \\
Cooperative & 0.04 & 0.19 & 0.04 & 0.19 \\
\end{tabular}

Panel B includes all firms with SIC codes 4121 (taxicabs) or 4119 (limousines), taxicab revenue $\geq \$ 10 \mathrm{~K}$, at least 2 taxicabs, and at least 2 taxicab fleets in their market (county) in both 1992 and 1997 . Note that Census Bureau restrictions prohibit publication of minimum and maximum variable values. 
Table 2 Diversification and the productivity of taxicab-specific assets

$T F P Q_{i 1997}-T F P Q_{i 1992}=a+B_{1} \sigma_{i}+X_{i c} \boldsymbol{B}_{c}+e_{i}$

\begin{tabular}{|c|c|c|c|c|c|c|c|c|}
\hline \multicolumn{9}{|c|}{ Dependent variable $=$ Change in total factor productivity $(\triangle \mathrm{TFPQ})$} \\
\hline & (1a) & & (1b) & & (2a) & & $(2 b)$ & \\
\hline & OLS & & 2SLS & & OLS & & 2SLS & \\
\hline Taxicab to limousine & -0.45 & $* * *$ & -0.53 & $* * *$ & -0.41 & $* * *$ & -0.46 & ** \\
\hline $\begin{array}{l}\text { Middle } 1 / 3 \text { of } 1992 \\
\text { size (taxi K) distribution }\end{array}$ & & & & & $\begin{array}{l}-0.08 \\
(0.09)\end{array}$ & & $\begin{array}{r}-0.09 \\
(0.09)\end{array}$ & \\
\hline Largest $1 / 3$ of 1992 size & & & & & 0.15 & * & 0.13 & \\
\hline size (taxi K) distribution & & & & & $(0.07)$ & & $(0.10)$ & \\
\hline Corporation & & & & & $\begin{array}{l}-0.06 \\
(0.06)\end{array}$ & & $\begin{array}{l}-0.05 \\
(0.07)\end{array}$ & \\
\hline$\Delta$ County taxicab & & & & & 0.20 & $* * *$ & 0.20 & $* * *$ \\
\hline ownership rate $_{-i}$ & & & & & $(0.07)$ & & $(0.07)$ & \\
\hline $\begin{array}{l}\Delta \log (\text { taxicabs in } \\
\left.\text { the county } y_{-i}\right)\end{array}$ & & & & & $\begin{array}{r}0.02 \\
(0.03)\end{array}$ & & $\begin{array}{r}0.02 \\
(0.03)\end{array}$ & \\
\hline $\begin{array}{l}\Delta \log (\text { limousines in } \\
\left.\text { the county }{ }_{-\mathrm{i}}\right)\end{array}$ & & & & & $\begin{array}{l}-0.02 \\
(0.03)\end{array}$ & & $\begin{array}{l}-0.02 \\
(0.03)\end{array}$ & \\
\hline$\Delta \log ($ county pop.) & & & & & $\begin{array}{r}-0.20 \\
(0.29)\end{array}$ & & $\begin{array}{r}-0.21 \\
(0.28)\end{array}$ & \\
\hline Constant & $\begin{array}{r}0.30 \\
(0.07)\end{array}$ & $* * *$ & $\begin{array}{r}0.38 \\
(0.09)\end{array}$ & $* * *$ & $\begin{array}{r}0.39 \\
(0.11)\end{array}$ & $* * *$ & $\begin{array}{r}0.42 \\
(0.15)\end{array}$ & $* * *$ \\
\hline $\mathrm{N}$ & 560 & & 560 & & 560 & & 560 & \\
\hline $\mathrm{R}^{2}$ & 0.08 & & $\mathrm{n} / \mathrm{a}$ & & 0.12 & & $\mathrm{n} / \mathrm{a}$ & \\
\hline $1^{\text {st }}$ stage summary statistic & & & & & & & & \\
\hline F-statistic & & & 32 & & & & 10 & \\
\hline t-statistic on IV & & & -5.6 & & & & -5.3 & \\
\hline $\mathrm{R}^{2}$ & & & 0.05 & & & & 0.12 & \\
\hline $\mathrm{N}$ & & & 560 & & & & 560 & \\
\hline
\end{tabular}

Standard errors are robust and clustered at the market (county) level

Results in this table include all firms with SIC codes 412100 (taxicabs) or 411920 (limousines), taxicab revenue $\geq \$ 10 \mathrm{~K}, \geq 2$ taxicabs, and $\geq 2$ taxicab fleets in their market (county) in both 1992 and 1997.

The excluded status category is incumbents who did not laterally diversify. The excluded size category is the smallest $1 / 3$ of the 1992 size distribution measured in terms of dollars of taxicab capital.

The 2SLS estimates use IV = HHI index of lagged (1992) market (county) concentration of limousines. The Durbin-Wu-Hausman test rejects the null hypothesis that the instrument is not necessary at the $1 \%$ level $\left[\chi^{2}=33\right.$ in column $\left.2(b)\right]$

*** significant at the $1 \%$ level, ** significant at the 5\% level, * significant at the $10 \%$ level 
Table 3 Diversification and organizational rigidity

$T F P_{i 1997}=a+\boldsymbol{X}_{\sigma \theta}\left(\boldsymbol{\sigma}_{i}, \boldsymbol{\theta}_{i}\right) \boldsymbol{B}_{\sigma \theta}+\boldsymbol{X}_{i c} \boldsymbol{B}_{c}+e_{i}$

\begin{tabular}{|c|c|c|c|c|c|c|c|c|}
\hline \multirow[b]{2}{*}{$\begin{array}{l}\text { Taxicab to limousine } \\
\text { diversifier }\end{array}$} & \multicolumn{4}{|c|}{$\begin{array}{c}\text { Taxicab-only } \\
\text { Dep. var. = total factor } \\
\text { productivity (TFPQ) }\end{array}$} & \multicolumn{4}{|c|}{$\begin{array}{l}\text { Pooled (Taxicab and Limo) } \\
\text { Dep. var. = multi-factor } \\
\text { productivity (TFP) }\end{array}$} \\
\hline & $\begin{array}{r}(1) \\
-0.66 \\
(0.09)\end{array}$ & $* * *$ & $\begin{array}{r}(2) \\
-0.61 \\
(0.08)\end{array}$ & $* * *$ & $\begin{array}{r}(3) \\
-0.84 \\
(0.08)\end{array}$ & $* * *$ & $\begin{array}{r}(4) \\
-0.85 \\
(0.08)\end{array}$ & $* * *$ \\
\hline $\begin{array}{l}\text { Taxicab and } \\
\text { limousine start-up }\end{array}$ & $\begin{array}{r}-0.67 \\
(0.08)\end{array}$ & $* * *$ & $\begin{array}{r}-0.62 \\
(0.07)\end{array}$ & $* * *$ & $\begin{array}{r}-0.84 \\
(0.05)\end{array}$ & $* * *$ & $\begin{array}{r}-0.79 \\
(0.04)\end{array}$ & $* * *$ \\
\hline $\begin{array}{l}\text { Taxicab only } \\
\text { start-up }\end{array}$ & $\begin{array}{l}-0.23 \\
(0.09)\end{array}$ & $* *$ & $\begin{array}{r}-0.17 \\
(0.08)\end{array}$ & $* *$ & $\begin{array}{r}-0.26 \\
(0.08)\end{array}$ & $* * *$ & $\begin{array}{r}-0.18 \\
(0.08)\end{array}$ & $* *$ \\
\hline $\begin{array}{l}\text { Middle } 1 / 3 \text { of the } 97 \\
\text { size (taxi K) distrib. }\end{array}$ & & & $\begin{array}{r}0.02 \\
(0.10)\end{array}$ & & & & $\begin{array}{r}-0.01 \\
(0.05)\end{array}$ & \\
\hline $\begin{array}{l}\text { Largest } 1 / 3 \text { of the ' } 97 \\
\text { size (taxi K) distrib. }\end{array}$ & & & $\begin{array}{r}0.16 \\
(0.09)\end{array}$ & $*$ & & & $\begin{array}{r}0.14 \\
(0.08)\end{array}$ & $*$ \\
\hline Corporation & & & $\begin{array}{r}0.16 \\
(0.08)\end{array}$ & $*$ & & & $\begin{array}{r}0.21 \\
(0.04)\end{array}$ & $* * *$ \\
\hline $\begin{array}{l}\text { Log (total county } \\
\left.\text { taxicabs }_{-\mathrm{i}}\right)\end{array}$ & & & $\begin{array}{r}0.07 \\
(0.06)\end{array}$ & & & & $\begin{array}{r}0.07 \\
(0.03)\end{array}$ & $*$ \\
\hline $\begin{array}{l}\text { Log (total county } \\
\text { limousines }_{-i} \text { ) }\end{array}$ & & & $\begin{array}{r}-0.06 \\
(0.05)\end{array}$ & & & & $\begin{array}{r}-0.03 \\
(0.03)\end{array}$ & \\
\hline $\begin{array}{l}\text { Limousine SIC } \\
\text { indicator }\end{array}$ & & & & & $\begin{array}{r}0.11 \\
(0.06)\end{array}$ & $* *$ & $\begin{array}{r}0.09 \\
(0.06)\end{array}$ & \\
\hline Constant & $\begin{array}{r}0.43 \\
(0.06)\end{array}$ & $* * *$ & $\begin{array}{r}0.12 \\
(0.16)\end{array}$ & & $\begin{array}{r}0.33 \\
(0.05)\end{array}$ & $* * *$ & $\begin{array}{r}-0.04 \\
(0.06)\end{array}$ & \\
\hline $\begin{array}{l}\mathrm{N} \\
\mathrm{R}^{2}\end{array}$ & $\begin{array}{r}1106 \\
0.13\end{array}$ & & $\begin{array}{r}1106 \\
0.16\end{array}$ & & $\begin{array}{r}2341 \\
0.20\end{array}$ & & $\begin{array}{r}2341 \\
0.23\end{array}$ & \\
\hline $\begin{array}{l}\Delta \text { Incumbent TFPQ } \\
-\Delta \text { Start-up TFPQ }\end{array}$ & $\begin{array}{r}-0.21 \\
(0.09)\end{array}$ & $* *$ & $\begin{array}{r}-0.17 \\
(0.09)\end{array}$ & $* *$ & $\begin{array}{r}-0.26 \\
(0.11)\end{array}$ & $* *$ & $\begin{array}{r}-0.23 \\
(0.10)\end{array}$ & $* *$ \\
\hline
\end{tabular}

Standard errors are robust and clustered at the market (county) level. The results in the "Taxicab-only" regressions include all firms with SIC codes 412100 (taxicabs) or 411920 (limousines), taxicab revenue $\geq \$ 10 \mathrm{~K}, \geq 2$ taxicabs, and $\geq 2$ taxicab fleets in their market (county) in either 1992 or 1997 . The "Pooled" regressions include all firms with SIC codes 412100 (taxicabs) or 411920 (limousines), taxicab + limousine revenue $\geq \$ 10 \mathrm{~K}, \geq 2$ vehicles, $\geq 2$ fleets in their market in 1997 . The excluded status category is incumbents who did not laterally diversify. The excluded size category is "smallest 1/3 of the 1997 size distribution measured in dollars of taxicab capital" (or taxicab+limousine capital).

*** significant at the $1 \%$ level, ** significant at the 5\% level, * significant at the $10 \%$ level 


\section{Appendix: Estimating the Costs of Organizational Rigidity}

Let firm i's productivity be completely characterized by a function $\mathrm{f}$ that transforms two parameters $\theta$ and $\sigma$ into output plus a noise term $\varepsilon$ that has mean zero, where $\theta$ captures whether the firm is a start-up or incumbent firm, and $\sigma$ captures whether the firm is a one product firm or a two product firm:

$$
\begin{aligned}
\operatorname{TFP}_{\mathrm{i}}=\mathrm{f}(\theta, \sigma)+\varepsilon_{\mathrm{i}} & \\
\theta & =1 \text { if it is an incumbent and zero otherwise } \\
\sigma & =1 \text { if the firm is a two product firm and zero otherwise. }
\end{aligned}
$$

No incumbent firms were two-product firms in the pre-period so that when $\operatorname{TFP}=\mathrm{f}(1,1)$ we hypothesize that there is an interaction effect between $\theta$ and $\sigma$ that captures the cost of organizational change:

$\mathrm{C}(\delta)=\mathrm{g}\left(\theta^{*} \sigma\right)>0$ when $\theta=1$ and $\sigma=1$ and is zero otherwise.

Therefore,

$\mathrm{E}[\mathrm{f}(1,1)]=\mathrm{E}[\mathrm{f}(1,0)]+\mathrm{E}[\mathrm{f}(0,1)]-\mathrm{C}(\delta)$.

The second hypothesis assumes more experienced firms are more productive so that $\mathrm{E}[\mathrm{f}(1,0)]-\mathrm{E}[\mathrm{f}(0,0)]>0$. I have confined the analysis to the case where increasing levels 
of firm scope leads to increased coordination costs so that by assumption $E[f(0,1)]-$ $\mathrm{E}[\mathrm{f}(0,0)]<0 .{ }^{24}$ I therefore normalize $\mathrm{E}[\mathrm{f}(0,0)]=0$ without loss of generality.

I test the assumption (A1) that incumbents generally outperform start-ups by netting the average productivity of one-product incumbents against one-product start-ups:

(i) $\mathrm{E}[\mathrm{f}(1,0)]-\mathrm{E}[\mathrm{f}(0,0)]=\mathrm{V}(\theta=1)$.

Where $\mathrm{V}(\theta=1)$ is the average value of being an incumbent. A1 predicts that $\mathrm{V}(\theta=1)>0$.

The gross effect of incumbency and change in firm scope can be computed by subtracting the average productivity of two-product start-ups from the average productivity of lateral diversifiers:

(ii) $\mathrm{E}[\mathrm{f}(1,1)]-\mathrm{E}[\mathrm{f}(0,1)]$

$$
=[\mathrm{E}[\mathrm{f}(1,0)+\mathrm{E}[\mathrm{f}(0,1)]-\mathrm{C}(\delta)]-\mathrm{E}[\mathrm{f}(0,1)]=\mathrm{V}(\theta=1)-\mathrm{C}(\delta) .
$$

Netting equations (i) and (ii) recovers the cost of change in firm scope. The second hypothesis predicts that $\mathrm{C}(\delta)>0$.

\footnotetext{
${ }^{24}$ Note that if taxicabs and limousines are complementary with respect to output the bias would lead us to reject the second hypothesis when we should not.
} 